\title{
Accountability, rendición de cuentas y controles a la administración. ¿Cómo funcionan en Argentina según el ordenamiento jurídico vigente?*
}

\author{
Diana Carolina Valencia Tello" \\ Vera Karam de Chueiri"** \\ Recibido: mayo de 2015 \\ Evaluado: julio de 2015 \\ Aprobado: noviembre de 2015
}

\section{RESUMEN}

En América Latina diversos escándalos de corrupción y malversación de recursos públicos están minando la confianza de la ciudadanía en las instituciones democráticas, en todos los países de la región. La impunidad existente en casos de corrupción y la falta de accountability dejan en duda a la democracia y la legitimidad de las instituciones. El presente artículo tiene por objetivo analizar, primero, la importancia del fortalecimiento del accountability en América Latina para mejorar la calidad de la democracia en la región para, después, analizar específicamente el caso de Argentina, buscando identificar cuáles son los vacíos dentro del ordenamiento jurídico que generan grandes riesgos de corrupción y evaluar cómo sería posible mejorar esta situación.

Palabras clave: accountability, rendición de cuentas, controles a la administración, corrupción, democracia.

Este artículo hace parte de la línea de investigación sobre Derecho de Estado, dentro del Núcleo de Constitucionalismo y Democracia de la Facultad de Derecho de la Universidad Federal del Paraná y fue financiado por la CAPES.

** Profesora Visitante de la Facultad de Derecho de la Universidad Federal del Paraná. Especialización en Derecho Administrativo y Ambiental. Maestría, Doctorado y Post-Doctorado en Derecho de Estado en la Universidad Federal del Paraná. Dirección electrónica: dianacvt@hotmail.com

*** Profesora de Derecho Constitucional de los Programas de graduación y posgraduación de la Universidad Federal del Paraná. Visiting Researcher en Yale Law School 2015-2016. Dirección electrónica: vkchueiri@ gmail.com 


\title{
Accountability, Reporting, and Management Control. How Does This Work in Argentina According to the Legal System in Force?
}

\begin{abstract}
In Latin America, several corruption and public money embezzlement scandals have damaged the confidence citizens have in democratic institutions from all the countries of the region. Existing impunity in cases of corruption and the lack of accountability leaves democracy and legitimacy of institutions in a difficult position. Present article is intended to analyze the importance of accountability strengthening in Latin America as a way of improving quality of democracy in the region and then analyzing the specific case of Argentina, as an attempt to identify the loopholes within the legal system that result in important corruption risks and to evaluate the way to improve this situation.
\end{abstract}

Key words: Accountability; reporting; management controls; corruption; democracy. 


\section{INTRODUCCIÓN}

En América Latina diversos escándalos de corrupción y malversación de recursos públicos minan la confianza de la ciudadanía en las instituciones democráticas en todos los países de la región. La impunidad existente en casos de corrupción y la falta de rendición de cuentas dejan en duda la democracia y la legitimidad de las instituciones.

La corrupción es un concepto difícil de definir y de medir, razón por la cual no existe una regla totalmente aceptada y confiable que pueda determinar con total seguridad el nivel de corrupción en un país. No obstante, existen índices de percepción de la corrupción, siendo el más aceptado y difundido el de la ONG Transparencia Internacional.

En los últimos años, Argentina ha empeorado dramáticamente el índice de percepción de la corrupción elaborado por Transparencia Internacional. En el último informe de 2014, Argentina ocupó la posición número 107 entre los 174 países analizados. Tan solo hace dos décadas, en 1995, Argentina ocupaba la posición número 24. Entonces la pregunta que surge es: ¿cuáles son las causas que han permitido el aumento de la percepción de corrupción en Argentina?

Según Pablo Secchi, director ejecutivo de Poder Ciudadano (fundación que apoya la elaboración del índice de Transparencia Internacional en Argentina), entrevistado por el diario La Nación, "Esta caída en el índice refleja la total ausencia de esfuer- zos en nuestro país en materia de lucha contra la corrupción. Los organismos de control fueron reducidos a su mínima expresión durante los últimos años convirtiéndolos en actores intrascendentes" (Dapelo, 2014, 3 de diciembre).

Para Transparencia Internacional, aunque en Argentina existe legislación que busca prevenir la corrupción y existen instituciones encargadas de luchar contra la corrupción, también existen importantes vacíos legales dentro del ordenamiento jurídico que generan grandes riesgos de corrupción. Entre las recomendaciones dadas por la ONG, se resaltan dos. La primera, mejorar el "accountability" en el país, buscando la aplicación adecuada de la ley para detener la impunidad; y la segunda, fortalecer las instituciones encargadas de luchar contra la corrupción. (Trasparencia Internacional, 2014).

En el mundo anglosajón se utiliza el término accountability para referirse a esa preocupación constante sobre las limitaciones y restricciones al poder, utilizando controles y contrapesos dentro de los ordenamientos jurídicos para impedir que el poder esté concentrado o fuera de supervisión por parte de la mayoría. El concepto político de accountability no tiene una traducción específica en español y por ello, a veces se traduce como control, rendición de cuentas o fiscalización.

En este contexto, el presente artículo tiene por objetivo analizar, en primera instancia, la importancia del fortalecimiento del "accountability" en América Latina 
para mejorar la calidad de la democracia en la región, para después, estudiar específicamente el caso de Argentina, buscando identificar cuáles son los vacíos dentro del ordenamiento jurídico que generan grandes riesgos de corrupción y cómo sería posible mejorar esta situación. La metodología adoptada es de naturaleza cualitativa y descriptiva, mediante el análisis del ordenamiento jurídico vigente, documentos oficiales, libros, periódicos, artículos en revistas indexadas y portales electrónicos reconocidos.

Para realizar este estudio, se analizará cómo la opacidad de la esfera pública en América Latina ha sido una constante histórica que limita la calidad de nuestras democracias, para después, en la segunda sección, delimitar los conceptos de accountability, rendición de cuentas y controles. En la tercera sección se estudiará específicamente el concepto de control a la Administración Pública, para después analizar cómo es el funcionamiento de los controles a la Administración Pública en Argentina.

\section{OPACIDAD DE LA ESFERA PÚBLICA EN AMÉRICA LATINA}

El Estado de derecho supuso una nueva forma de entender el poder público desde el principio de legalidad, derrumbando versiones patrimonialistas y subjetivas que dominaron el viejo régimen. Aún así, a pesar del esfuerzo por prohibir la arbitrariedad, el oscurantismo, el secreto y la opacidad en el ejercicio del poder, en el modelo democrático todavía existen estos fantasmas porque "(...) el problema del poder, además de jurídico, o precisamente por ello, requiere de un fuerte compromiso personal con los más elementales principios democráticos" (Rodríguez-Arana, 2009, p. 335).

En América Latina, la fragilidad del derecho y de la esfera pública puede encontrarse, desde tiempos remotos, en los ordenamientos jurídicos y en la cultura jurídica existente, ya que la captura del Estado por algunos grupos minoritarios impide algunas (o muchas) veces la aplicación efectiva del derecho o la implementación de controles efectivos al poder. Al respecto, el Centro Latinoamericano para la Administración y el Desarrollo CLAD (2010) afirma:

Uno de los legados más importantes para entender América Latina es la fragilidad de la esfera pública. Por siglos, las tendencias patrimonialistas y privatistas tuvieron gran impacto en nuestros países. Esto se manifestó, por un lado, en el dominio sobre una vasta parcela de cargos públicos por parte de oligarquías políticas $y$, por otro lado, en la capacidad de influencia que tuvo el poder económico sobre las decisiones gubernamentales, conduciendo a una captura del Poder Público por parte de las empresas privadas. En estas dos situaciones, las decisiones generalmente eran tomadas sin que hubiese un escrutinio público sobre dichas decisiones. La opacidad, y no la transparencia, era una marca del Estado.

Desde la década de los años ochenta, América Latina entró en una nueva etapa 
de democratización, caracterizada por la consolidación de procesos electorales competitivos, conforme a estándares internacionales, que determinan que las elecciones deben ser justas, competitivas, regulares y abiertas a la participación de todos los segmentos de la comunidad política, independientemente de su ideología y de las raíces culturales étnicas o socioeconómicas (Moisés, 2010, p. 80-81).

La democratización de América Latina fue un gran avance para la consolidación de Estados de derecho constitucionales, respetuosos de los derechos humanos que dejaron atrás épocas de dictaduras y regímenes autoritarios que legitimaban el uso de la fuerza de forma discrecional, para mantener el "orden", impidiendo toda critica a la acción del gobierno y violando derechos humanos fundamentales.

Aún así, las nuevas democracias todavía conviven con culturas políticas autoritarias, las cuales impiden de diversas formas la crítica a la administración, al limitar la participación activa de la ciudadanía, ocultar información, evitar la rendición de cuentas, y utilizar la corrupción y la malversación de fondos públicos para concretar intereses particulares. Esto, porque todavía los grupos más poderosos continúan ejerciendo influencias cuestionables dentro de los diversos procesos políticos.

En los últimos años, múltiples escándalos de corrupción y malversación de recursos públicos han minado la confianza de la ciudadanía en las instituciones democráticas en todos los países de la región. La impunidad existente en casos de corrupción y la falta de rendición de cuentas dejan en tela de juicio a los principios democráticos de igualdad ante la ley, objetividad, responsabilidad, economía y eficiencia del gasto público, entre otros.

En el caso de Argentina, Manzetti (2014, p.178) afirma que la consolidación del poder de los Kirchners entre mayo de 2003 y junio de 2013 (periodo en el que realizó el estudio), se ha caracterizado por un ejercicio autoritario del poder que ignora los principios del gobierno limitado y de accountability. Para Manzetti, el Congreso no cuenta con independencia real frente al ejecutivo debido a multiples factores, tales como la dependencia de las provincias a la transferencia de recursos federales, la falta de experiencia de los congresistas y la falta de personal capacitado de apoyo a los congresistas. Las deficiencias del accountability horizontal entre los poderes de gobierno no solo facilitan la corrupción; también dificulta el buen desarrollo de los asuntos públicos y de la democracia en conjunto. Opinión similar tienen Levitsky y Murillo (2008, p. 24), quienes advierten que la consolidación del poder de los Kirchner representa la falta de supervisión y de accountability sobre el ejecutivo, lo que aumenta los riesgos de errores en la política y la corrupción.

En este contexto, es evidente que, si queremos fortalecer los Estados de derecho constitucionales y democráticos en la región, es fundamental ampliar los mecanismos de control, rendición de cuentas 
o accountability, tal y como explicaremos a continuación.

\section{ACCOUNTABILITY, RENDICIÓN DE CUENTAS Y CONTROLES A LA ADMINISTRACIÓN PÚBLICA}

La democracia en el siglo XXI no puede limitarse al derecho de votar y ser elegido. La complejidad de nuestras sociedades y la existencia de pluralidad de intereses legítimos hacen necesario que se amplíen los espacios de participación y control en las diversas entidades del Estado.

La democracia como forma de gobierno se sustenta en dos ideas fundamentales a nuestro entender: la primera, la elección libre y autónoma de los gobernantes por periodos de tiempo; y la segunda, no menos importante, la obligación de los agentes públicos de rendir cuentas sobre sus decisiones y acciones asumiendo la responsabilidad ante los ciudadanos.

En el mundo anglosajón se utiliza el término accountability para referirse a esa preocupación constante sobre las limitaciones y restricciones al poder, mediante el uso de controles y contrapesos dentro de los ordenamientos jurídicos, para impedir que el poder esté concentrado o fuera de supervisión por parte de la mayoría. El concepto político de accountability no tiene una traducción específica en español y por ello, a veces se traduce como control, rendición de cuentas o fiscalización.

Para Schedler, la traducción más cercana es la rendición de cuentas, aunque existen matices que separan los dos conceptos. Uno de los matices más importantes hace referencia a que:

\begin{abstract}
[...] mientras accountability conlleva un sentido claro de obligación, la noción de rendición de cuentas parece sugerir que se trata de un acto voluntario, de una concesión generosa del soberano que rinde cuentas por virtud y voluntad propia no por necesidad. Podemos precisar entonces que accountability es la rendición obligatoria de cuentas (Schedler, 2008, p. 11).
\end{abstract}

El politólogo argentino Guillermo O’Donnell (1999) fue uno de los primeros en estudiar el concepto de accountability, al diferenciar dos modelos principales. El primero, accountability vertical, que desde su perspectiva se refiere a las relaciones de control de la sociedad hacia el Estado, mediante elecciones, opinión pública, movimientos sociales, etc. El segundo, accountability horizontal, que se refiere a los controles establecidos entre agencias del Estado, es decir, son los mecanismos de control institucionalizados en las diversas administraciones públicas para impedir abusos de poder por parte de agentes del Estado en el desarrollo de sus competencias.

Estos conceptos son criticados por Schedler (2008, p. 35-34), por considerar que el poder es por definición un fenómeno relacional difícil de medir e identificar en el complejo mundo de la política democrática, donde las relaciones de poder son desiguales y fluctuantes. 
Para corregir esta imprecisión algunos autores como Schmitter (1999) y Sklar (1999) han introducido la noción de controles diagonales u oblicuos, dado que los actores políticos en un sistema democrático: "(...) nunca se enfrentan en perfecta igualdad ni absoluta desigualdad de poder" (Schedler, 2008, p. 35), causando que todas las relaciones de rendición de cuentas sean "diagonales" u "oblicuas". Aquí, los conceptos de rendición de cuentas y control se asimilan a la búsqueda por limitar efectivamente el poder dentro de un sistema democrático, que cuenta con sistemas de pesos y contrapesos entre los diferentes poderes públicos.

\section{El concepto de control también presenta} numerosos problemas al momento de tratar de identificar una única definición, ya que es una palabra que puede tener múltiples significados dependiendo del contexto en que se utilice, aunque su finalidad principal sea la de hacer efectivas las limitaciones al poder ${ }^{1}$.

\footnotetext{
Esta realidad es expuesta por Aragón (1999, p.55-56) al comparar el significado de la palabra control en diferentes idiomas, así: "Aunque suele decirse que en el idioma inglés "control" se refiere a dominio, a diferencia de lo que ocurre en francés, en el que el término se restringe más bien a "comprobación", lo cierto es que la amplitud del significado se manifiesta en varios idiomas y en otros. En inglés significa "mando", "gobierno", "dirección", pero también "freno" y "comprobación"; en francés, "registro" "inspección", "verificación", pero también "vigilancia", "dominio" y "revisión"; en alemán (kontrolle), "comprobación", "registro", "vigilancia" pero también, "intervención", "dominio" y "revisión"; en italiano (controllo), "revisión", "inspección", "verificación", pero también "vigilancia", "freno" y "mando". El diccionario de la Real Academia Española otorga a la palabra los siguientes significados: "inspección", "fiscalización", "intervención", "dominio", "mando",
}

Teniendo en cuenta las dificultades existentes para establecer una definición única sobre los conceptos de accountability, rendición de cuentas y control, aquí queremos llamar la atención sobre los puntos en común que tienen estos conceptos, adoptando una definición general. Esta definición indica la existencia de una relación de poder entre una persona que tiene la obligación de informar y explicar sobre sus acciones y decisiones a otra persona, quien, a su vez, tiene el derecho de exigir explicaciones e imponer algún tipo de sanción por un comportamiento inadecuado. Esta definición general se asemeja en gran medida a la dada por Schedler en cuanto a la rendición de cuentas así:

$$
\begin{aligned}
& \text { [...] La rendición de cuentas } \\
& \text { abarca de manera genérica tres } \\
& \text { maneras diferentes para prevenir } \\
& \text { y corregir abusos de poder: obliga } \\
& \text { al poder a abrirse a la inspección } \\
& \text { pública, lo fuerza a explicar y } \\
& \text { justificar sus actos y lo supedita } \\
& \text { a la amenaza de sanciones. Los } \\
& \text { tres aspectos en su conjunto } \\
& \text {-información, justificación y cas- } \\
& \text { tigo- convierten a la rendición } \\
& \text { de cuentas en una empresa mul- } \\
& \text { tifacética (Schedler, 2008, p. 35). }
\end{aligned}
$$

En los ordenamientos jurídicos latinoamericanos es más común encontrar la palabra "control" antes que rendición de cuentas y definitivamente no se en-

\footnotetext{
"preponderancia". Si del análisis puramente lingüístico pasamos al examen de la utilización de la palabra se hace en las normas jurídicas, la pluralidad de significados no desaparece, en cuanto que los ordenamientos suelen encontrarse el término "control" referido como reconoce Galeotti, a fenómenos muy diversos [...]"
} 
cuentra la palabra accountability. Por esta razón, en este trabajo nos referiremos a los controles a la administración bajo el entendido de incluir elementos de los conceptos de accountability y de rendición de cuentas antes mencionados, dentro de un sistema de gobierno democrático.

\section{CONTROLES A LA ADMINISTRACIÓN PÚBLICA}

Para efectos de delimitar el objeto de estudio del presente artículo, entendemos por control a la Administración Pública toda actividad de verificación sobre la gestión pública, con la finalidad de corroborar el cumplimiento de las normas aplicables y la realización de objetivos y programas previamente planificados especialmente en el poder ejecutivo. De forma general, el control a la Administración Pública está compuesto por dos tipos de controles complementarios: el control interno y el control externo.

El control interno es el nivel más básico de limitación en la Administración Pública, que permite a la entidad verificar el cumplimiento de las normas aplicables y la realización de objetivos previamente propuestos en los diversos equipos de trabajo. Es un control que debe existir en toda entidad pública en forma de autolimitación, auto-gestión y auto-control, con la finalidad de dar coherencia y previsibilidad a las diferentes actividades que se desarrollan día a día.

Al ser el control interno el nivel más básico de control, debe ser aplicado por todos los funcionarios públicos en todos los niveles de gobierno, para evitar extralimitaciones en el cumplimiento de sus atribuciones, y garantizar el cumplimiento de metas y objetivos previamente trazados.

El control interno puede ser visto como un tipo de accountability vertical, con base en la existencia de una jerarquía piramidal dentro de las burocracias, buscando asegurar el control de los aparatos administrativos, conforme los objetivos previamente establecidos por los niveles superiores de gobierno quienes, a su vez, en regímenes democráticos, deben rendir cuentas por sus acciones y decisiones a la ciudadanía. En este orden de ideas, la existencia de sistemas de control interno confiables, basados en métodos y procedimientos técnicos, ayuda no solo a soportar la gestión ante cualquier organismo de control, sino que también otorga la información necesaria para una rendición de cuentas integral a la ciudadanía.

Por su parte, el externo es un control realizado por una entidad competente del más alto nivel de gobierno para verificar el cumplimiento de normas y objetivos, al velar por el buen manejo de los recursos públicos y el cumplimiento de la misión institucional por parte de otras entidades públicas. Para que el control externo sea objetivo e imparcial, la independencia de los órganos competentes al ejercer el control es fundamental, ya que, si su gestión depende de factores políticos, el control a la gestión pública se puede tornar subjetivo y parcial, afectando con esto su transparencia y efectividad. 
El control externo puede ser visto como un tipo de accountability horizontal, ya que la rendición de cuentas es realizada por órganos especializados del más alto nivel de gobierno, lo que puede describirse como una relación entre iguales, en donde las entidades están en "posiciones de poder equiparables", permitiendo la existencia de sistemas de pesos y contrapesos, esenciales para el funcionamiento de la democracia. Sin embargo, para Schedler:

\section{[...] la agencia pública que exige cuentas en serio no puede estar literalmente en igualdad de condi- ciones con la agencia que rinde cuentas. Por lo menos, en la es- fera de su jurisdicción que puede ser estrechamente circunscrita, el controlador debe ser más poder- oso que el controlado. [...] deben contar con la autonomía y la au- toridad suficientes para investigar sospechas, exigir justificaciones e imponer sanciones, en donde sea necesario (Schedler, 2008, p. 35).}

En América Latina, las democracias se han caracterizado por instituir sistemas presidenciales de gobierno (Carpizo, 2009, p. 39), razón por la cual el control sobre el poder ejecutivo ha sido históricamente limitado, ya que los órganos de control muchas veces no se encuentran en igualdad de condiciones frente al poder ejecutivo. Aún así, todos los Estados cuentan con entidades especializadas para realizar el control externo, las cuales se denominan de forma general entidades fiscalizadoras superiores (EFS). En la región, existen dos tipos básicos de EFS: los tribunales de cuentas, y las contralorías. Teniendo en cuenta las anteriores consideraciones, a continuación, analizaremos el marco constitucional y legal de los controles a la Administración Pública en Argentina.

\section{EL CONTROL A LA ADMINISTRACIÓN PÚBLICA EN ARGENTINA}

La Constitución vigente en Argentina es una de las más antiguas en la región. Fue aprobada por una Asamblea Constituyente en 1853, y hasta el momento ha sido reformada siete veces. La última reforma ocurrió en 1994. Inicialmente, la Constitución se refería al control de los recursos del Estado, de forma muy simple en el artículo 75 , que establece la obligación de instituir un organismo fiscal federal que deberá asegurar la representación de todas las provincias y la ciudad de Buenos Aires. Así, desde 1853, los controles a la administración en Argentina no han sido parte relevante del diseño constitucional $y$, en consecuencia, su desarrollo se ha realizado mediante la promulgación de leyes ordinarias.

La Ley 428 de 1870 estableció los primeros controles financieros a la administración, que buscaban establecer normas y procedimientos en materia presupuestal y contable. Esta Ley creó como órgano responsable del control administrativo de la hacienda del Estado a la Contaduría General de la Nación, sin realizar diferenciaciones importantes entre el control interno y el control externo (Sindicatura General de la Nación, 2003). 
En 1956 se creó el Tribunal de Cuentas de la Nación como órgano de control externo de la hacienda pública, dotándolo de independencia para llevar a cabo su misión. Los miembros del Tribunal eran nombrados por el Poder Ejecutivo, por conducto del Ministerio de Hacienda. Por lo tanto, solo hasta 1956 se estableció un organismo con funciones jurisdiccionales de control externo, mientras que la Contaduría General continuó como encargada del control interno y del asesoramiento contable a las entidades públicas (Sindicatura General de la Nación, 2003).

Posteriormente, en 1974 se creó la Corporación de Empresas Nacionales mediante la Ley 20.558 con la finalidad de controlar las diversas actividades ejecutadas por las empresas y sociedades del Gobierno Nacional. Con esto, se buscaba contar con un sistema de control más integral y ágil que ayudara dentro de la gestión empresarial. En 1978, la Ley 21.801 reemplazó a la Corporación de Empresas Nacionales por la Sindicatura General de las Empresas Públicas (SiGeP), entidad creada como órgano descentralizado, con personería jurídica; una entidad encargada de controlar la gestión y la legalidad de los actos de las empresas (Sindicatura General de la Nación, 2003).

Al analizar los antecedentes de los sistemas de control de la Administración Pública en Argentina, Despouy, actual Auditor General de la Nación, sostiene que los controles establecidos en el ordenamiento jurídico eran insuficientes para promover un buen desempeño en el conjunto de la Administración Pública. En sus palabras, Despouy afirma:

\begin{abstract}
Evaluando en perspectiva, el sistema de control previsto originariamente en la Constitución de 1853, basado en el control reciproco de poderes, resultó insuficiente para promover un buen desempeño en la administración estatal. Las nociones de gobernabilidad, buena gestión, administración correcta y equilibrada, eficacia estatal, adecuado manejo de las finanzas públicas, control efectivo del uso de fondos públicos y tantos otros aspectos, sumados a los requisitos de transparencia en la gestión gubernamental, acceso a la información pública, participación ciudadana, mostraban la necesidad de perfeccionar los sistemas tradicionales de control institucional y político. Esto apareció claramente reflejado en el espíritu de la reforma de 1994, que incorporó una serie de derechos, garantías e institutos que respondían a estos nuevos paradigmas (Despouy, 2012A, p. 9).
\end{abstract}

En la década de los años noventa Argentina (al igual que el resto de países latinoamericanos) tuvo que implementar reformas al Estado para hacer frente a la crisis fiscal y al pago de la deuda. La Ley 24.156 de 1992 denominada "Ley de Administración Financiera y de los Sistemas de Control del Sector Público Nacional" fue sancionada en el marco del proceso de reforma al Estado iniciado con la Ley 23.696, por la que se declaró en estado de emergencia la prestación de los servicios públicos (Sindicatura General de la Nación, 2003). 
Bajo la declaración de emergencia, la Ley 24.156 de 1992 estableció la conformación de los sistemas de control interno y control externo en Argentina, determinando que la responsabilidad por el control interno sería de la Sindicatura General de la Nación (SIGEN), organismo vinculado a la Presidencia de la República, y la responsabilidad por el control externo sería de la Auditoría General de la Nación (AGN), organismo vinculado al Congreso Nacional. Adicionalmente, la Ley estableció el régimen de responsabilidad de los funcionarios públicos, con la finalidad de garantizar la rendición de cuentas ante la sociedad.

Teniendo en cuenta que antes de esta Ley el control externo a la Administración Pública era realizado por el Tribunal de Cuentas de la Nación, podemos verificar que desde 1992 se realizó un cambio de modelo en la forma de realizar el control en la Administración Pública en Argentina, como analizaremos a continuación.

\subsection{Marco constitucional y legal}

En materia de control externo a la administración, la Reforma a la Constitución de 1994 otorgó a la Auditoria General de la Nación (AGN) el reconocimiento constitucional, ya que el artículo 85 instituyó la AGN como órgano de asistencia técnica del Congreso para la realización del control externo en Argentina, así:

Artículo 85. El control externo del sector público nacional en sus aspectos patrimoniales, económi- cos, financieros y operativos, será una atribución propia del Poder Legislativo.

El examen y la opinión del Poder Legislativo sobre el desempeño y situación general de la administración pública estarán sustentados en los dictámenes de la Auditoría General de la Nación.

Este organismo de asistencia técnica del Congreso, con autonomía funcional, se integrará del modo que establezca la ley que reglamenta su creación y funcionamiento, que deberá ser aprobada por mayoría absoluta de los miembros de cada Cámara. El presidente del organismo será designado a propuesta del partido político de oposición con mayor número de legisladores en el Congreso.

Tendrá a su cargo el control de legalidad, gestión y auditoría de toda la actividad de la administración pública centralizada y descentralizada, cualquiera fuera su modalidad de organización, y las demás funciones que la ley le otorgue.

Intervendrá necesariamente en el trámite de aprobación o rechazo de las cuentas de percepción e inversión de los fondos públicos.

Al analizar este artículo, podemos verificar que el control externo a la Administración Pública en Argentina es competencia del Congreso, y la AGN es creada como un organismo de asistencia técnica, con autonomía funcional. La AGN necesita para su correcto funcionamiento de ley reglamentaria que debe ser aprobada por 
mayoría absoluta de los miembros de cada Cámara. La Constitución Nacional -CNtambién establece que la AGN deberá ser presidida por un (1) presidente, quien deberá ser designado a propuesta del partido político de oposición con mayor número de legisladores en el Congreso.

Hasta la fecha, el Congreso no ha aprobado ninguna ley que reglamente la creación y el funcionamiento de la AGN, lo que puede deberse, en parte, al exigente requisito constitucional de aprobación por mayoría absoluta de cada Cámara. Por esta razón, la AGN continúa desarrollado sus actividades con base en la Ley 24.156 de 1992, lo que genera contradicciones importantes con la reforma constitucional de 1994. En principio, hemos identificado dos contradicciones fundamentales que afectan el debido desarrollo del control externo en Argentina.

La primera contradicción es que la AGN no cuenta con autonomía funcional frente al Congreso Nacional, conforme lo ordena la Constitución, pues bajo la actual normativa el Congreso es quien establece la estructura básica, normas de funcionamiento y distribución de funciones. La segunda contradicción importante tiene que ver con la dirección de la AGN, ya que la Ley 24.156 determina un colegio de siete auditores nombrados por el Congreso Nacional de mayoria oficialista, y la Reforma constitucional de 1994 determina que la AGN será presidida por un (1) presidente, quien deberá ser designado a propuesta del partido político de oposición con mayor número de legisladores en el Congreso.
Al respecto, el Presidente de la AGN, Leandro Despouy, en el informe de gestión sobre el control público en Argentina 2002-2012, considera que la Ley de Administración Financiera y la Constitución establecen órdenes normativos contradictorios, lo que genera numerosos conflictos en el desarrollo de las actividades del control externo. En el citado informe, Despouy afirma:

La debilidad más notoria que ofrece la arquitectura institucional de la AGN se sitúa esencialmente en la yuxtaposición de dos órdenes normativos que encarnan filosofías distintas y, en algunos casos, opuestas, de los órganos de control. La Ley de administración financiera, que significó un progreso considerable en materia presupuestaria, arrastró notorias deficiencias en el ámbito del control gubernamental, ya que cercenó aspectos esenciales que hacen a la autonomía e independencia de la AGN. Por el contrario, la CN además de conferir rango constitucional a la AGN, al presidente de la institución y al control externo del Estado le otorga la autonomía e independencia propias de una EFS. A diferencia de la Ley 24.156, la CN se aproximó más al principio de control por oposición cristalizado en la consigna "el que gana gobierna y el que pierde controla". Por ello, es que confiere la presidencia del organismo al partido de oposición con mayoría de representantes en el Congreso (Despouy, 2012B, p.27). 
Para el Presidente de la AGN, la falta de reglamentación del texto constitucional ha sido la fuente principal de litigios y controversias públicas. En este contexto, las preguntas que surgen son: ¿Quién representa finalmente al organismo y es su autoridad máxima? ¿El presidente, que es la única figura constitucional o el Colegio de Auditores que se rige por la Ley 24.156 que regulaba anteriormente a la AGN y que tal como lo prueba la práctica, hace que los auditores nombrados por los bloques oficialistas de las dos cámaras sean mayoría? ¿Puede estar el control externo encargado de controlar la gestión del Estado que lleva a cabo el oficialismo, en manos de un organismo con predominio oficialista? (Despouy, 2012B, p.27).

Efectivamente, la ausencia de reglamentación del artículo 85 de la Constitución Nacional - $\mathrm{CN}$ - constituye una notoria falta del Congreso. Esta demora en la reglamentación del control externo ha posibilitado y abierto un debate que, en muchos casos, ha frenado la actividad de la AGN sobre todo con respecto a la aprobación de los informes en su versión original por parte del Colegio de Auditores, dominado por el bloque oficialista, como se analizará a continuación.

\subsection{Los informes de auditoria de la AGN y el acceso a la información}

La indebida injerencia del Congreso sobre la gestión de la AGN se evidencia claramente en la necesidad de aprobación de los informes de auditoría por parte del Colegio de Auditores. Cuando los informes de auditoría son finalmente aprobados por el Colegio de Auditores, deben ser notificados a la Comisión Parlamentaria Mixta Revisora de Cuentas, salvo que el Colegio de Auditores haya decidido la reserva del informe, reserva que deberá ser justificada, conforme la facultad de reserva excepcional contemplada en el inciso f) artículo 119 de la Ley 24.156 a la mencionada Comisión².

Los informes catalogados como "reservados" que deben ser archivados bajo esta denominación por la Oficina de Actuaciones Colegiadas de la entidad no pueden ser publicados hasta tanto no exista autorización de la Comisión Parlamentaria correspondiente ${ }^{3}$. La AGN ha reglamentado la reserva de informes mediante la Resolución 66 del 23 de mayo de $2003^{4}$. Sin embargo, esta normativa no aclara cuales son los criterios objetivos que deberán sustentar la decisión de reserva de los informes, razón por la cual este es un vacío legal que genera opacidad.

Por otra parte, los informes que han sido aprobados por el Colegio de Auditores

\footnotetext{
Artículos 1 y 2 de la Disposición 151 de septiembre 6 de 2002. Expedida por la Auditoría General de la Nación. Disponible en: http://www.agn. gov.ar/informes-normativas Fecha de Consulta: 20/04/2015

3 Art. 30 de la Resolución 77 del 15 de agosto de 2002 "Por la cual se expiden las normas básicas para la planeación institucional, sistema de control de los procesos de auditoria y para la formación de actuaciones de auditoría." Disponible en: http:// www.agn.gov.ar/informes-normativas Fecha de Consulta: 20/04/2015

4 Modificado en su artículo $4^{\circ} \mathrm{del}$ anexo I de la resolución $\mathrm{N}^{\circ}$ 66/03 reglamentaria del artículo 30 de la Resolución 77/02 A.G.N. Disponible en: http:// www.agn.gov.ar/informes-normativas Fecha de Consulta: 20/04/2015
} 
sin reserva se publican en la página web de la institución para consulta de toda la ciudadanía. En los últimos años, se ha evidenciado una mejora sustantiva del control externo en materia de transparencia y participación ciudadana, en razón a la decisión de publicar los informes de la AGN en página web, inmediatamente después de ser enviados al Congreso.

Anteriormente, la prohibición de publicar los informes de la AGN alentó graves sospechas sobre la utilización de los informes para otros fines y, en cualquier caso, el moroso y opaco tratamiento en el Congreso menguaba considerablemente su impacto. Así para la AGN, la publicación de los informes tuvo un efecto vitalizador en la medida en que los distintos sectores involucrados en la sociedad-usuarios, consumidores, etc.-, advirtieron la relevancia de las comprobaciones y las auditorias (Despouy, 2012B).

En el informe de gestión del 2012, la AGN hace un llamado de atención a la Administración Pública en razón a las dificultades encontradas en las entidades al momento de solicitar información relevante para las auditorías del control externo. En algunos casos, la AGN debió recurrir a la Justicia para que se entregara información. En uno de estos casos fue precisamente la Sindicatura General de la Nación -SIGEN-, organismo responsable por el control interno, la que se negó a entregar información, lo que representa un contrasentido entre organismos responsables por los controles a la administración, quienes deberían apoyarse permanentemente para lograr mejores resultados.
Estos eventos ejemplifican bien cómo la entidad que exige cuentas en serio no puede estar en igualdad de condiciones con la entidad que rinde cuentas, ya que para que los controles sean efectivos, es necesario que el controlador cuente con autonomía y autoridad suficientes para investigar hechos, exigir justificaciones e imponer sanciones cuando sea necesario (Schedler, 2008, p. 35).

\subsection{Relación de la AGN con el Congreso}

En el Congreso, la Comisión Parlamentaria Mixta Revisora de Cuentas - $\mathrm{CPMRC}^{5}$, influye decisivamente en la dinámica de la AGN, restringiendo de forma importante el buen desempeño del control externo en Argentina, en razón de tres evidencias fundamentales.

La primera evidencia trata sobre la falta de autonomia funcional de la AGN frente a la CPMRC, ya que esta comisión propone el programa de acción anual y el proyecto de presupuesto de la AGN remitiéndolo al poder Ejecutivo para su incorporación en el Presupuesto General de la Nación. Al respecto Despoy afirma:
Si se comparan los presupuestos de los países de América Latina y el Caribe, en cuanto al índice destinado a los respectivos órga- nos de control, se observa que el de Argentina es el más bajo; solo México presenta uno similar. En la última década, el presupuesto

Esta Comisión está compuesta por 6 senadores y 6 diputados elegidos simultáneamente en igual forma que los miembros de las Comisiones permanentes. Su periodo está limitado al periodo de elección. 
de la AGN ha oscilado entre un máximo del $0.06 \%$ y un piso del $0.04 \%$ del PIB. Son superiores los indicadores de los demás países de la región y bastante mayores los de naciones con desarrollo relativo más avanzado como Brasil, Chile y Colombia, con índices que oscilan entre el $0.11 \%$ y el $0.17 \%$. (Despouy, 2012A, p.16).

Adicionalmente, la Comisión Parlamentaria le encomienda a la AGN realizar estudios, investigaciones y dictámenes especiales y le fija plazos para los mismos; le requiere información sobre las actividades realizadas, analiza los informes periódicos de cumplimiento del programa de trabajo aprobado, efectúa las observaciones e indica las modificaciones que estime conveniente introducir y analiza la memoria anual de la Auditoría. El hecho de que el plan anual de la auditoría quede supeditado a la propuesta de la comisión parlamentaria indica para muchos la falta de autonomía funcional requerida para el ejercicio del control público, pese a que la Constitución otorga un reconocimiento formal a la AGN (Misas, 2006, p. 175).

La segunda evidencia trata sobre la revisión de la Cuenta de Inversión. Desde la reforma Constitucional de 1994 el Congreso debe aprobar el Presupuesto Nacional y examinar su ejecución mediante la revisión de la Cuenta de Inversión, la cual debe contar con un dictamen previo de la AGN. Al respecto, el informe de gestión de la AGN indica lo siguiente:

Este rol constitucional del Congreso no ha sido cumplido en forma acabada en todos los casos a lo largo de nuestra vida institucional. Hay largos periodos en que las cuentas de inversión no han sido tratadas por el Congreso y en otros se desconoce el resultado de dicho tratamiento al extremo de que resulta dificultoso reconstruir con precisión a lo largo de nuestra historia la suerte que ha corrido cada una de las Cuentas de Inversión. Lo cierto es que en 2002 el retraso en el examen de las cuentas de inversión de los años precedentes era considerable y la propia auditoría registraba también crecientes demoras en sus exámenes. Los esfuerzos de normalización de esta tarea por la AGN han sido mayúsculos y nos han permitido dar cumplimiento en término. En 2003 se aprobó la Cuenta de Inversión del año 1999, mientras que en 2011 trabajamos en la aprobación de la Cuenta de Inversión 2009. En ese sentido, cabe destacar el sostenido empeño de Oscar Lamberto, primero en el Congreso y luego en la AGN.

Acabamos de completar el examen del dictamen de la cuenta de 2010 y hemos dado inicio a la de 2011. En el Congreso no ha acontecido lo mismo y si bien se produjo una notoria mejoría en el tratamiento de la cuenta aún se registra déficits temporales significativos (Despouy, 2012B, p, 20-21).

El incumplimiento de la revisión de la Cuenta de Inversión por parte del Congreso y la AGN evidencia la poca eficacia del control externo en Argentina, ya que una 
de las razones fundamentales del control externo dentro de las democracias es el accountability o la rendición de cuentas entre los poderes públicos para verificar el cumplimiento de las leyes y la realización de los programas y metas establecidas en las diversas entidades, conforme el presupuesto inicialmente aprobado.

Finalmente, la tercera evidencia es aún más preocupante, puesto que, dada la falta de eficacia del control externo en Argentina en los últimos años, el Poder Ejecutivo ha tenido una amplia facultad para reasignar libremente las partidas presupuestales aprobadas por el Congreso a través de las leyes de Presupuesto. Según el informe de la AGN presentado por Despouy (2012B) en algunos ejercicios, el desvío de recursos entre el presupuesto aprobado por el Congreso y el finalmente ejecutado alcanzó el 30 $\%$, y en otros periodos el $20 \%$. La AGN tiene identificados siete organismos en donde se encuentran concentradas las modificaciones presupuestarias. Así, el Presupuesto está compuesto por partidas denominadas "discrecionales" (sujetas a decisión del Poder Ejecutivo), que permiten transferir considerables fondos a provincias, municipios, organizaciones de la sociedad civil y al sector privado. El total de transferencias discrecionales en el período 2000-2010 se incrementó 10 veces (1000\%) de 11 mil millones a 116 mil millones de pesos argentinos.

El incremento de las transferencias discrecionales del poder ejecutivo corrobora en parte la tesis de Manzetti (2014, p.178) sobre la falta de independencia del Con- greso frente al Poder Ejecutivo al momento de realizar accountability, en razón a la dependencia de los congresistas sobre las transferencias a las provincias.

\subsection{Relaciones con otras entidades fiscalizadoras locales}

Argentina es una república federal, dividida en 23 provincias y un distrito Federal, que es la Ciudad Autónoma de Buenos Aires. Del análisis de las leyes e informes del AGN se desprende que el control externo en Argentina está desconcentrado en cada Estado de la Federación, sin que exista ninguna legislación que determine requisitos mínimos para ejercer el control externo en el nivel territorial.

Debido a que Argentina no cuenta con normas que unifiquen los diferentes conceptos, procedimientos o mecanismos para aplicar los controles externos o internos en las entidades públicas de las provincias, cada Estado cuenta con instrumentos legales propios y autónomos en materia de control, generando que el sistema de accountability sea bastante complejo y dificil de administrar como puede verificarse en el Manual elaborado por la Fundación Poder Ciudadano (2008).

Otro ejemplo son las Constituciones de la Provincia de Salta (artículo 169) y de la Ciudad Autónoma de Buenos Aires (artículo 135) que establecen la Auditoría General como órgano encargado para ejercer el control externo posterior, excluyendo así la posibilidad del control preventivo. En contraste en 2006 y 2007, las consti- 
tuciones de las Provincias de Tucumán (artículo 78) y la de Corrientes (artículo 133) instituyeron el Tribunal de Cuentas, determinando que el control por él ejercido es preventivo (Atchabahian, 2006).

En este orden de ideas, en Argentina coexisten dos modelos de entidades fiscalizadoras en el nivel federal y territorial: las auditorías generales y los tribunales de cuentas, además de diversos modelos de control (preventivo y posterior), sin que existan normas generales que regulen aspectos minimos sobre los controles aplicables o sobre las relaciones entre los organismos de control. Los vacíos y la falta de coherencia de los sistemas juridicos aplicables deben provocar diversos conflictos e interpretaciones opuestas entre los diversos responsables de la gestión pública en Argentina, en los varios niveles de gobierno.

\subsection{Sistema de control interno}

Con relación al sistema de control interno para el gobierno federal, la Ley 24.156 en el artículo 100 determina que el sistema está conformado por la SIGEN, órgano normativo de supervisión y coordinación, así como por las unidades de auditoría interna (UAI) que deben ser creadas en cada jurisdicción y que dependerán jerarquicamente de la autoridad superior de cada organismo, en coordinación técnica con la SIGEN. La Ley establece que la autoridad máxima de cada entidad es la responsable por la implementación de un adecuado sistema de control interno, el cual debe incluir elementos de control previo y posterior incorporados en los planes de la organización y en los reglamentos y manuales de procedimiento.

De esta forma, el correcto desempeño de la SIGEN depende directamente del desempeño de las UAI en cada entidad pública. La SIGEN, al ser un órgano de supervisión y coordinación entre las UAI, tiene la potestad de comprobar la existencia del sistema de control interno en las entidades y puede hacer recomendaciones, procurando la existencia de controles integrales, esto es, buscando controles que abarquen aspectos vinculados a la legalidad, el presupuesto, las finanzas, el patrimonio, la gestión, la evaluación de programas, proyectos y operaciones de las entidades públicas, con base en criterios de economía, eficiencia y eficacia.

De esta forma, la Ley busca la existencia de controles integrales, los cuales no se limitan al control de legalidad y al control financiero, como en épocas anteriores; también buscan realizar control a la gestión mediante la aplicación de los principios de economía, eficiencia y eficacia en la Administración Pública.

Aquí debemos resaltar que la SIGEN aprobó mediante Resolución 173 de 2014 las Normas Generales de Control Interno que determinan los componentes mínimos que debe tener un sistema de control interno en las entidades públicas del gobierno federal. Consideramos que la elaboración de normas generales para la efectiva implementación de sistemas de control interno es un importante paso para mejorar la transparencia y la rendición de cuentas de todas las enti- 
dades públicas en Argentina. Aún así, se deberá analizar en el futuro el grado de implementación del sistema de control interno en cada entidad.

\section{CONCLUSIONES}

En la actual crisis institucional por la que atraviesan los Estados latinoamericanos debido en parte a los escándalos de corrupción, es fundamental fortalecer los mecanismos de accountability y rendición de cuentas entre los que se encuentran los controles a la Administración Pública, buscando mejorar la gestión pública, la transparencia y la participación ciudadana.

En el caso de Argentina identificamos que la falta de reglamentación de aspectos fundamentales de los órganos de control y de los procedimientos de control no solo es una fuente de conflicto entre funcionarios públicos y políticos en todos los niveles de gobierno, sino que también es la causa principal para la inexistencia de controles objetivos e imparciales que ayuden al buen desempeño de la Administración Pública y al desarrollo equilibrado de la democracia.

La inexistencia de reglas claras en materia de control impide que las instituciones competentes puedan limitar el poder de forma efectiva, ya que siempre existirán interpretaciones diversas y conflictuantes que impedirán el diálogo entre los funcionarios responsables. También impide la participación efectiva de los ciudadanos sobre el desempeño de las entidades públicas de su interés, lo que respresenta una limitación importante para el buen desarrollo de la democracia y la transparencia en Argentina.

Aún así, en los últimos años se evidencia mejoría en la forma de aplicar los controles y en la publicidad de los informes de los órganos de control. Los responsables por el control externo realizan análisis honestos sobre los principales desafíos que enfrentan al momento de realizar las auditorías y presentar los informes, lo que en nuestro concepto es un punto de partida importante para mejorar las deficiencias encontradas.

Consideramos que teniendo en cuenta las deficiencias encontradas en los sistemas de accountability en Argentina es fundamental que se inicie un debate profundo sobre la forma en que se deberían reglamentar los controles a la Administración Pública en el nivel federal y en las provicias, buscando fortalecer los organismos de control, los procedimientos de control y la inclusión de la ciudadanía en estos procesos.

En nuestro concepto, es necesario otorgar una mayor autonomía al Congreso frente al Poder Ejecutivo, así como también es necesario otorgar mayor autonomía a la AGN frente al Congreso. Adicionalmente, es importante que se acuerde un lenguaje común entre los organismos de control en los niveles federal y provincial, así como requisitos mínimos que deben observar los procedimientos de control, para simplificar los sistemas y hacerlos más efectivos. 
Estas reformas deben tener en cuenta que los controles a la Administración Pública no solo representan una forma de limitar el poder y evitar abusos en el desarrollo de competencias, sino que también deben representar una forma de legitimar la acción del Estado al permitir una mayor participación de la ciudadanía y mayor transparencia de las administraciones públicas.

\section{REFERENCIAS BIBLIOGRÁFICAS}

Aragón, M. (1999) Constitución y control de poder: introducción a una teoría constitucional del control. Bogotá: Universidad Externado de Colombia

Argentina. Corte Suprema de Justicia de la Nación/ Biblioteca del Congreso de la Nación. (2010). Constitución de la Nación Argentina. Publicación Bicentenario. (1a Ed). Disponible en http://bibliotecadigital. csjn.gov.ar/Constitucion-de-la-NacionArgentina-Publicacion-del-Bicent.pdf Fecha de Consulta: 15/02/2015.

Argentina. Provincia de Buenos Aires. (1994). Constitución de la Provincia de Buenos Aires. Disponible en http://www.gob.gba.gov. ar/dijl/constitucion.php Fecha de Consulta: 19/04/2015

Argentina. Provincia de Corrientes. (2007). Constitución de la Provincia de Corrientes. Disponible en https://www.corrientes.gov. ar/assets/articulo _ adjuntos/28/original/ Constitución _de_la _ Provincia de _ Corrientes.p $\overline{d f}$ ? 1377356446 Fecha de Consulta: 19/04/2015.

Argentina. Provincia de Salta. (1998). Constitución de la Provincia de Salta. Disponible en http://www.agpsalta.gov.ar/web/marconormativo/78-contenidos-agp/76-articulo169-de-la-constitucion-de-la-provincia-desalta Fecha de Consulta: 19/04/2015.
Argentina. Provincia de Tucumán. (2006). Constitución de la Provincia de Tucumán. Disponible en http://www.tribunaldecuentas. gov.ar Fecha de Consulta: 19/04/2015.

Atchabahian, A. (2006). Organismos de Control Externo en la Hacienda Pública: Importancia de su Raigambre Constitucional. Universidad de Buenos Aires. AAIII Simposio Nacional de Profesores Universitario de Contabilidad Pública. Catamarca (septiembre 2006). Disponible en www.elcontrolpublico.com.ar/ Fecha de Consulta: 15/02/2015.

Auditoría General de la Nación -AGN-. (2002). Disposición 151 de septiembre 6 de 2002. Disponible en http://www.agn.gov.ar/ informes-normativas Fecha de Consulta: 20/04/2015

Auditoría General de la Nación -AGN-. (2002). Resolución 77 del 15 de agosto de 2002, "Por la cual se expiden las normas básicas para la planeación institucional, sistema de control de los procesos de auditoria y para la formación de actuaciones de auditoría". Disponible en http://www.agn.gov. ar/informes-normativas Fecha de Consulta: 20/04/2015

Auditoría General de la Nación -AG-. (2003). Resolución N. 66/03 reglamentaria del artículo 30 de la Resolución 77/02 A.G.N. Disponible en: http://www.agn.gov.ar/ informes-normativas Fecha de Consulta: 20/04/2015

Carpizo, J. (2009). Concepto de Democracia y sistema de gobierno en América Latina. Bogotá: Universidad Externado de Colombia, Universidad Nacional Autónoma de México.

Centro Latino Americano de Administración para el Desarrollo -CLAD-. (2010). Gestión Pública Iberoamericana para el siglo XXI. Documento aprobado por la XL Reunión ordinaria del Consejo Directivo del CLAD. Santo Domingo. Disponible en http:// www4.congreso.gob.pe/DGP/ $\overline{\mathrm{CCEP} /}$ 
curso/2014/c-08-25-2014/materiales-CLAD. pdf Fecha de Consulta: 18/04/2015.

Despouy, L. (2012A). Informe del Presidente de la Auditoría General de la Nación. Auditoria General de la Nación. El Control público en Argentina. Realidades y Perspectivas. Cuestiones sustantivas abordadas en los informes de la Auditoría General de la Nación a lo largo de la década 2002-2012. Disponible en http://www.ucr.org.ar/data/material/ El-control-publico-en-Argentina--informecompleto.pdf Fecha de Consulta: 15/02/2015.

Despouy, L. (2012B). El control púbico en Argentina. Realidad y Perspectivas. Informe de Gestión 2002-2012. Síntesis Ejecutiva. Disponible en http://www.ucr.org.ar/data/ material/El-control-publico-en-Argentina-sintesis.pdf Fecha de Consulta: 15/02/2015.

Dapelo, S. (2014, 3 de diciembre). La Argentina volvió a caer en el índice de percepción de la corrupción de Transparencia Internacional. La Nación. Disponible en http://www. lanacion.com.ar/1748993-la-argentinavolvio-a-caer-en-el-indice-de-percepcionde-la-corrupcion-de-transparenciainternacional Fecha de consulta: 17/04/2015.

Fundación Poder Ciudadano. (2008). El fortalecimiento de la responsabilidad de los funcionarios públicos: Construyendo puentes entre organismos de control y la sociedad civil. Los casos de la Ciudad Autónoma de Buenos Aires, Mendoza y Santa Fe. Buenos Aires: Fundación Poder Ciudadano.

Ley 428 de 1870. Publicada 26 de septiembre de 1870. Contabilidad Nacional. Disponible en: http://www.infoleg.gov.ar/infolegInternet/ verNorma.do;jsessionid=D83767BDA1D7E3 0D1A7E91D102C9EC8E?id=48857 Fecha de Consulta: 01/05/2015.

Ley 20.558 de 1974. Corporación de Empresas Nacionales. Disponible en http:// consulta.bcn.gob.ar/bcn/Catalogo.

Revista Opinión Jurídica Universidad de Medellín
VerRegistro $\mathrm{CO}=108562$ Fecha de Consulta: 01/05/2015.

Ley 21.801 de 1978. Sindicatura General de Empresas Públicas. Disponible en http:// infoleg.mecon.gov.ar/infolegInternet/ anexos/180000-184999/180507/norma.htm Fecha de Consulta: 01/05/2015.

Ley 24.156 de 1992. Ley de Administración Financiera y de los Sistemas de Control del Sector Público Nacional. Disponible en http://infoleg.mecon.gov.ar/infolegInternet/ anexos/0-4999/554/texact.htm Fecha de Consulta: 15/02/2015.

Ley 25.152 de 1999. Establece las medidas a las cuales se deberán ajustar los poderes del Estado Nacional para la administración de los recursos públicos. Formulación del Presupuesto General de la Administración Nacional. Eficiencia y calidad de la gestión pública. Programa de Evaluación de Calidad del Gasto. Presupuesto plurianual. Información pública y de libre acceso. Créase el Fondo Anticíclico Fiscal. Disponible en http://www.infoleg.gov.ar/infolegInternet/ anexos/60000 -64999/60039/texact.htm Fecha de Consulta: 15/02/2015.

Levitsky, S. \& Murillo, M. V. (2008). Argentina: From Kirchner to Kirchner. Jornal of Democracy, Vol. 18, (N. ${ }^{\circ}$ ), pp. 16-30.

Manzetti, L. (2014). Accountability and Corruption in Argentina during the Kirchners'Era. Latin American Research Review, Vol. 49, (N.2). pp. 173-195.

Misas, G.; González, E.; Pérez, F.; Arango, J. E Chaux, H. (2006). Control Fiscal, modernización y lucha contra la corrupción: experiencias en América Latina. Bogotá: Contraloría General de la Republica, BID, SECAB.

Moisés, J. Á. (2010). Cultura política, instituições e democracia: lições da experiência brasileira. In: J. A. Moisés (Org.). Democracia e confiança: por que os cidadãos desconfiam 
das instituições publicas? (pp. 16-35). São Paulo: Edusp.

O’Donnell, G. (1999). Horizontal Accountability in New Democracies. In: A. Schedler, L. Diamond \& M. F. Plattner (Eds.). The SelfRestraining State: Power and Accountability in New Democracies (pp. 29-51). Boulder E Londres: Lynne Rienner Publishers.

Rodriguez-Arana, J. (2009). Aproximación al derecho administrativo constitucional. Bogotá: Universidad Externado.

Schedler, A. (2008). ¿Qué es la rendición de cuentas? México: Instituto Federal de Acceso a la Información Pública -IFAI-

Schmitter, P. (1999). The Limits of Horizontal Accountability. In: A. Schedler, L. Diamond \& M. F. Plattner (Eds). The Self-Restraining State: Power and Accountability in New Democracies (pp.59-62). Boulder $\mathcal{E}$ Londres: Lynne Rienner Publishers.

Sklar, Richard (1999) Democracy and Constitutionalism. In: A. Schedler, L.
Diamond \& M. F. Plattner (Eds.). The Self-Restraining State: Power and Accountability in New Democracies (pp. 53-58). Boulder \& Londres: Lynne Rienner Publishers.

Sindicatura General de la Nación. Presidencia de la República de Argentina. (2003). Ley 24.156 de 1992. Ley de Administración Financiera y de los Sistemas de Control del Sector Público Nacional. Titulo VI" Del Sistema de Control Interno" Texto Institucional Anotado, Comentado y Concordado. Disponible en http://www.sigen.gov.ar/ ley24156/ley24156concordado.pdf Fecha de consulta: 21/02/2015

Sindicatura General de la Nación. Presidencia de la República de Argentina. (2014.) Resolución 173 de 2014. Disponible en http://www.sigen. gov.ar/normativa/pdfs/RES01722014448500. pdf Fecha de Consulta: 20/04/2014.

Transparencia Internacional. (2014). Argentina. Disponible en https://www.transparency. org/country\#ARG Fecha de consulta: 17/04/2015. 
